\title{
Global prevalence estimates of three chronic musculoskeletal conditions: club foot, juvenile idiopathic arthritis and juvenile systemic lupus erythematosus
}

Mona Dave, Judith Rankin, Mark Pearce and Helen E. Foster ${ }^{*}$ (D)

\begin{abstract}
Background: Musculoskeletal (MSK) conditions are a major source of morbidity and disability. There is a lack of global comparable data on the burden of MSK conditions in children and young people. Our aim was to estimate the global prevalence of three MSK conditions - Talipes Equinovarus (Clubfoot), Juvenile Idiopathic Arthritis (JIA) and Juvenile Systemic Lupus Erythematosus (JSLE).

Methods: Using reported prevalence rates, age-stratified population data within the World Bank Data Bank in 2017 and United Nations country classification, we estimated the prevalence of these MSK conditions in $<5$ year olds (clubfoot) and < 16 year olds (JIA and JSLE) across the world.

Results: We estimated that in 2017, there were $\sim 675,061<5$ year olds with clubfoot among $675,100,000<5$ year olds, 2,069,246< 16 year olds with JIA and 206,931 < 16year olds with JSLE per 2,069,000,000 < 16 year olds, totalling $\sim 2,951,238$ with one of these conditions. Disease prevalence was greatest in Asia (South Asia), followed by Africa, Americas, Europe and Oceania.

Conclusions: An estimated 3 million children and young people globally are currently living with either clubfoot, JIA or JSLE; many in Asia and Africa. Further work is needed urgently to engage with global stakeholders to work together to improve access to effective care for the many who are affected and reduce the otherwise adverse lifelong impact on their health, quality of life and the impact on society.
\end{abstract}

Keywords: Global Health, Prevalence, Burden, Musculoskeletal, JIA, JSLE, Clubfoot

\section{Background}

The importance of musculoskeletal conditions in children and young people

Musculoskeletal (MSK) conditions are a leading cause of disability and morbidity and encompass conditions within rheumatology and orthopaedics as well as being the consequences of trauma and obesity. MSK

\footnotetext{
* Correspondence: h.e.foster@newcastle.ac.uk

Population Health Sciences Institute, Newcastle University, The Medical School, Framlington Place, Newcastle upon Tyne, Tyne and Wear NE24HH, UK
}

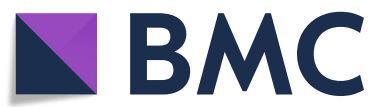

C C The Author(s). 2020 Open Access This article is licensed under a Creative Commons Attribution 4.0 International License, which permits use, sharing, adaptation, distribution and reproduction in any medium or format, as long as you give appropriate credit to the original author(s) and the source, provide a link to the Creative Commons licence, and indicate if changes were made. The images or other third party material in this article are included in the article's Creative Commons licence, unless indicated otherwise in a credit line to the material. If material is not included in the article's Creative Commons licence and your intended use is not permitted by statutory regulation or exceeds the permitted use, you will need to obtain permission directly from the copyright holder. To view a copy of this licence, visit http://creativecommons.org/licenses/by/4.0/ The Creative Commons Public Domain Dedication waiver (http://creativecommons.org/publicdomain/zero/1.0/) applies to the data made available in this article, unless otherwise stated in a credit line to the data.

conditions in adults are a major contributor to the global non-communicable diseases (NCDs) burden [1] and a priority for the global community to address [2-4] in the World Health Organisation (WHO) strategy for Universal Health Coverage [5]. Compared to $43.9 \%$ in 1990, NCDs accounted for $61.4 \%$ of global disability adjusted life years (DALYs) in the recent Global Burden of Disease report $[1,4]$ with the shift in disease burden from communicable to NCDs being more apparent in Low and Middle Resource Income countries (LRIC, MRIC). 
What is less clear, however, is the global burden of MSK conditions for individuals under the age of 18 years; there is a paucity of population data, especially in the most populated parts of the world [4]. In the UK, it is estimated that 1 in 8 children are affected by MSK conditions [6] - many are self-limiting or related to trauma although there are also serious MSK conditions with potential to be life threatening or cause severe disability if untreated. With advances in treatments for many MSK diseases, it is more important than ever to address inequity in access to care and to include children (who represent at least $20 \%$ of the global population, [7]) in strategies to reduce MSK disability across the life course.

The purpose of our work is to inform the 'bigger picture' and to estimate global prevalence of three MSK conditions in children and young people using population based methods [7]. This is a pragmatic approach in the absence of robust global population studies and provides a novel perspective to inform dialogue to address unmet need.

\section{Methods}

\section{MSK conditions}

The chosen MSK conditions are Talipes Equinovarus ('Clubfoot'), Juvenile Idiopathic Arthritis (JIA) and Juvenile Systemic Lupus Erythematosus (JSLE). The rationale for their inclusion was the evidence base of estimated prevalence rates, the importance of early diagnosis, and the importance of access to the right care to optimise clinical outcomes.

Clubfoot can affect one or both feet, commonly occurring in isolation, but may also be associated with other congenital anomalies $[8,9]$. Clubfoot in most cases can be effectively treated using the validated Ponseti method $[10,11]$ but without appropriate treatment can result in pain, disability and social handicap [12]. In this report, we use the term 'clubfoot' to represent isolated structural clubfoot. We use the term 'prevalence' in the under 5 year old age group, rather than incidence, as we do not know how many affected foetuses may have been 'lost' through early miscarriage and the condition is congenital. Prevalence rates of clubfoot vary between countries and racial groups; for this study we used an estimated prevalence rate of 1 in 1000 children based on reports from Europe [8] and North America [9].

JIA is a heterogeneous group of diseases with markedly improved clinical outcomes since the introduction of highly effective immunosuppressives and specialist care $[13,14]$. Prevalence studies are predominantly reported from Caucasian populations in Europe, North America and Australia with further evidence of variance in the prevalence of JIA subtypes in different ethnic groups and countries [15-20]; to our knowledge there are no population based studies from Africa or Asia. Such variation in prevalence rates reflect historical challenges in disease classification, ascertainment and referral biases but may also reflect true disease variation within different ethnic populations [15]. For the purpose of our work, we have used the estimated prevalence of 1 in 1000 based on the pooled prevalence data [15] and have not attempted to estimate JIA subtypes, or address variation by age, gender or ethnicity.

JSLE is a multisystem disease with serious, potentially life threatening organ involvement [21-24] and reported to be more common and severe in non-Caucasians with worse clinical outcomes [21, 23, 25-27]; to our knowledge there are no population based prevalence studies in Asia or Africa. For the purpose of this study, we have assumed a prevalence of 10 in 100,000 based on the United States (US) Medicaid programme covering a multi-racial population [22]; we have not attempted to address variation in prevalence estimates by age, gender or ethnicity.

\section{Data sources}

The World Bank Group (WBG) [7] online Databank provides free access to a range of datasets related to global development which can be downloaded in a range of formats. For our study, population data for 2017 were downloaded from the 'Population estimates and projections database' within the WBG Databank for every country available within the database $(n=217)$ and stratified by age in single years from 0 to 15 years for males and females separately. The total population of countries (all ages) was extracted similarly. Information on geographic regions and sub-regions for classification of countries, was taken from the United Nations (UN) Statistics Division [28].

\section{Data management}

Each country was manually assigned to its corresponding region and sub-region as classified by the UN [28] with the exception of Cyprus and Turkey which were classified as being in - Asia, Western Asia - by the UN [28] - but were re-classified to - Europe, Southern Europe - for the purposes of our analysis. Grouping of countries within their respective regions and sub-regions is shown in Additional file 1: Appendix A. Countries within the WBG Databank, differ from those within the UN Statistics Division. Countries with missing population data or a missing UN regional classification were excluded from our datasets and not included in any further analysis.

\section{Estimation of prevalence rates}

The population of $<5$ years olds was calculated by summing the population within each age band from 0 to 4 
years for males and females separately. These were then summed to give the total population of all children $<5$ years old by country, region and sub-region. The same process was undertaken to calculate the population of < 16 year olds using the population within each age band from 0 to 15 years. Estimated prevalences were calculated for 2017 using the reported prevalence rates of $1 /$ 1000 for clubfoot, 1/1000 for JIA and 10/100,000 for JSLE and the 2017 population of $<5$ year olds (for clubfoot) and $<16$ year olds (for JIA and JSLE) by country, region and sub-region using the following equation: Estimated prevalence of MSK condition= Reported prevalence rate $X$ Population. Data management and analysis were undertaken within Microsoft Excel and Stata version 14 .

\section{Results}

Table 1 summarises the data available in 2017 that were used to establish the global prevalences of the selected MSK conditions. Over 200 countries and almost 7.5 billion people (with just over 2 billion $<16$ year olds) were included in the analysis. Across all included countries, we estimated over 675,000 children $<5$ years of age living with clubfoot, over 2 million $<16$ year olds with JIA and over 200,000 with JSLE. Overall, we estimated nearly 3 million children were living with one of these conditions in 2017 (Fig. 1) with the data stratified by UN region and sub-region (Figs. 2 and 3 respectfully). Further analysis described the relative prevalence in different countries within the UN regions and sub-regions (Additional file 1: Appendix B). Asia (in particular Southern and Eastern Asia) had the highest estimated numbers of individuals with clubfoot, JIA and JSLE followed by
Africa, the Americas and Europe, with Oceania having the lowest estimated numbers for all three conditions. The distribution across each UN region can be seen in Fig. 2. Most clubfoot burden was concentrated across three sub-regions: Southern Asia, Eastern Asia and Eastern Africa, whilst $51 \%$ of both JIA burden and JSLE burden was concentrated across these same regions. When further stratifying analysis by sub-region, we found Southern Asia had the highest estimated case numbers for clubfoot $(176,462)$; $26 \%$ of clubfoot burden was distributed within this sub-region. This was followed by Eastern Asia (95,085 estimated cases, 14\%) and Eastern Africa (66,158 estimated cases, $10 \%)$. Southern Asia also had the highest estimated numbers of JIA cases (571, 572 ) with $28 \%$ of disease burden distributed across this sub-region. This was followed by Eastern Asia (297,333 estimated cases, 14\%) and Eastern Africa (187,787 estimated cases, 9\%). A similar pattern was seen for JSLE with 57,157 estimated cases in Southern Asia, representing $28 \%$ of disease burden, followed by Eastern Asia (29, 733 estimated cases, 14\%) and Eastern Africa (18,779 estimated cases, 9\%). The data are presented for each country (Additional file 1: Appendix C). In absolute terms, the countries with highest numbers of CYP with the exemplar conditions reflect the overall population sizes; in descending order these are India, China, Nigeria, Pakistan, Indonesia and the United States.

\section{Discussion}

Our work has taken a pragmatic approach to estimate global prevalence of three MSK conditions and using WBG population data from 2017, suggests that nearly 3 million individuals have at least one of clubfoot, JIA or

Table 1 Summary of the World Bank Group Data (2017) used in the analysis

\begin{tabular}{|c|c|}
\hline Variable & $\mathrm{N}$ \\
\hline Countries listed in World Bank Group Data & 217 \\
\hline Countries with missing UN region data & 2 \\
\hline Countries with missing World Bank population data & 23 \\
\hline Countries excluded from estimate calculations (data not available) & 25 \\
\hline Countries included in analysis & 192 \\
\hline Regions listed in UN Statistics Division & 5 \\
\hline Sub-regions listed in UN Statistics Division & 22 \\
\hline $\begin{array}{l}\text { Total population }<5 \text { years old across all countries with population data } \\
\text { Male: Female }\end{array}$ & $\begin{array}{l}6.75 \times 10 \wedge 8 \\
(675,100,000) \\
1.07: 1.00\end{array}$ \\
\hline $\begin{array}{l}\text { Total population }<16 \text { years old across all countries with population data } \\
\text { Male: Female }\end{array}$ & $\begin{array}{l}2.07 \times 10 \wedge 9 \\
(2,069,000,000) \\
1.07: 1.00\end{array}$ \\
\hline Total population across all countries included in analysis & $\begin{array}{l}7.49 \times 10 \wedge 9 \\
(7,494,205,912)\end{array}$ \\
\hline Proportion of total population $<5$ years old & $9.01 \%$ \\
\hline Proportion of population $<16$ years old & $27.61 \%$ \\
\hline
\end{tabular}




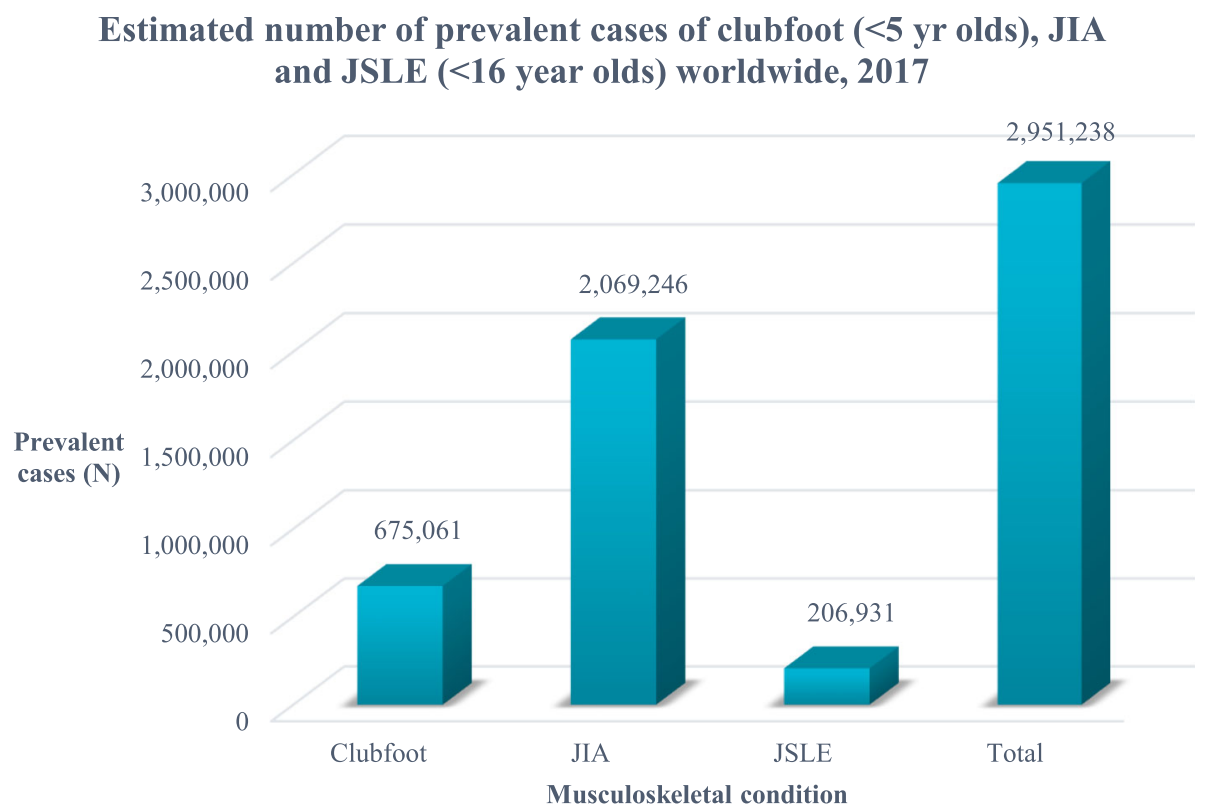

Fig. 1 Total estimated number of cases of clubfoot, JIA and JSLE across all countries included in analysis, 2017. The totals here are the sums of individual country data and will therefore be slightly different to the total when calculated by summing region data or sub-region data in subsequent figures due to rounding error

JSLE. Given that our analysis is limited to three conditions and we have not included trauma, then clearly the true MSK prevalence around the world is much higher. If we were to use our pragmatic model with the 2017 estimated global population of $2.07 \times 10^{9}$ young people aged under 16 years and a reported prevalence 1 in 8 [6] having an MSK presentation of one kind or another, then we estimate nearly 26 million individuals are likely to be affected.
This work aims to inform dialogue about the MSK contribution to NCDs in children and the need for strategies to include a life course approach. In the absence of robust population based studies from many parts of the world, our work demonstrates many are living with MSK conditions, mostly in Asia and Africa and reflecting regions with high populations.

This information is important as the regions with highest estimates of children affected do not have robust

Estimated number of children with a musculoskeletal condition in 2017 by UN region

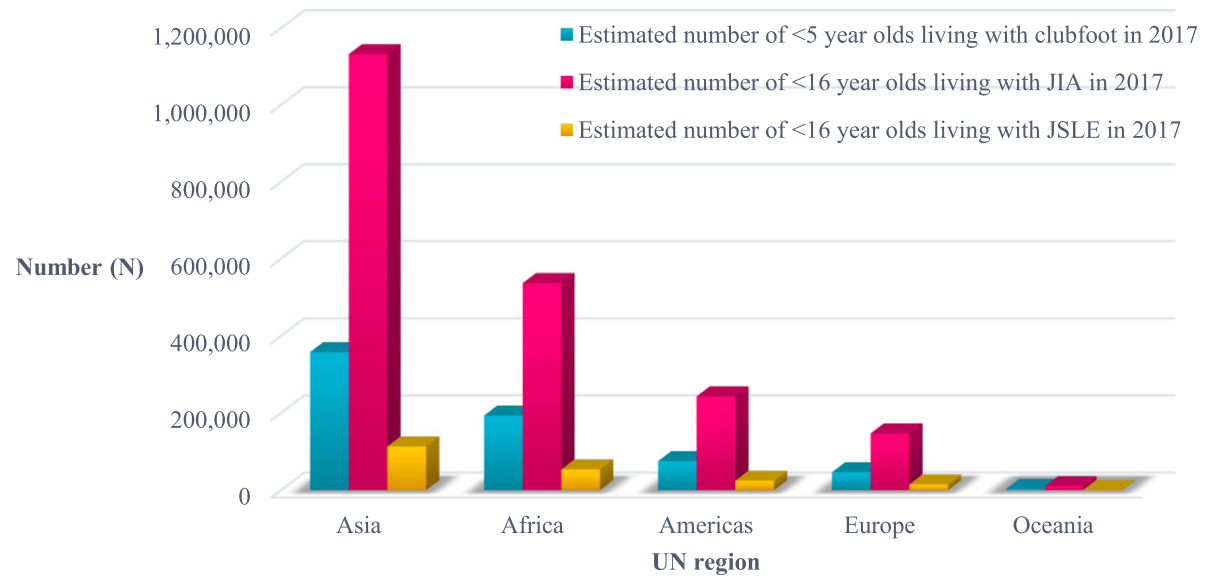

Fig. 2 Estimated number of children in 2017 with clubfoot, JIA and JSLE by UN region 


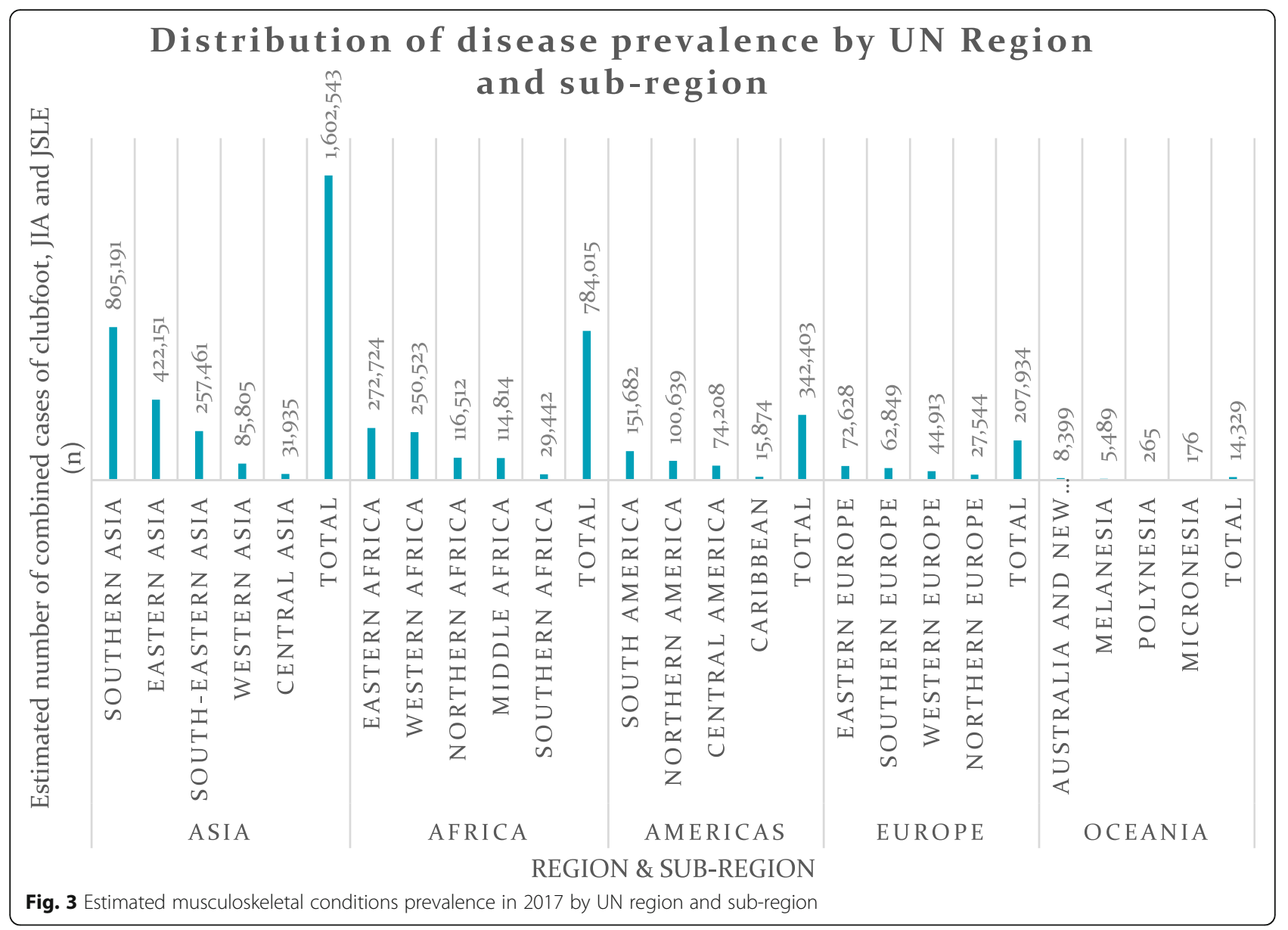

population studies and many of the countries are LRIC. Consequently, it is likely that many affected children have little or no access to specialist care. Recent evidence reports worse clinical outcomes in JIA for countries with lower Gross Domestic Product [16]; it is possible that the same will be true for JSLE and clubfoot. JSLE remains a major cause of mortality in many parts of the world with late presentation and lack of treatments being available $[18,29,30]$. MSK conditions may be less prevalent than other NCDs such as diabetes [31] or inflammatory bowel disease [32], but the key message for public health systems is that the selected MSK conditions are treatable and disability can be largely avoided. In the case of clubfoot, the interventions is largely through physiotherapy at relatively low cost and significant benefit [11] and for many rheumatic diseases significant improvement can be observed with immunosuppressive treatments [13].

To address unmet need, there are many challenges to consider including awareness, workforce capacity, models of health care, and funding [18, 30, 33-35]. The WHO Global Burden Disability 2018 report [1] describes the health care workforce shortage in many parts of the world as being critical, more so in Asia and Africa and for the care of children [36]. Such parts of the world are most vulnerable to the burden of MSK disease given more 'pressing' health care need to address poverty, infection and malnutrition in health care resource limited environments.

There are several limitations in our study. We based our estimates on available reported prevalence rates for each condition and assumed stable prevalence over time. There is a spectrum of prevalence rates for JIA largely from Caucasian populations [15]; we used an average prevalence of 1 in 1000 and this may not be representative in terms of population or demographics (age stratification, gender or ethnicity) of individual countries. We did not attempt to address the reported variation in disease phenotype across racial groups in JIA $[16,17]$ or JSLE [25] or clubfoot [9]. Additionally, our calculations were subject to rounding error. Despite these limitations, we consider the data to be pragmatic estimates of the selected conditions and if anything, likely to be an underestimate. Comparison with historical population datasets for JIA from the UK [37] and Scandinavia [20] suggest that our estimates are reasonable, at least for countries 
with predominantly Caucasian populations. Our work highlights need for robust epidemiological data, especially from Africa and Asia, to inform dialogue about MSK burden in children and to include other MSK conditions such as Slipped Capital Femoral Epiphysis (SCFE) [38] where there is evidence of delay and early (surgical) intervention to improve clinical outcomes.

In conclusion, our work suggests that there are many children and young people with the selected MSK conditions around the world and many in regions challenged by limited resources and other health care problems. The Paediatric Global MSK Task Force [39] aims to raise awareness about the inequity in access to right care and a timely need for intervention. We hope that this study will facilitate dialogue with key stakeholders to leverage action.

\section{Supplementary information}

Supplementary information accompanies this paper at https://doi.org/10. 1186/s12969-020-00443-8.

Additional file 1: Figures 4-6. Estimated number of children and young people in 2017 living with clubfoot, JIA or JSLE respectively, within each sub-region. Figure 4. Estimated cases of clubfoot in 2017 by UN sub-region. Figure 5. Estimated cases of JIA in 2017 by UN sub-region. Figure 6. Estimated cases of JSLE in 2017 by UN sub-region. Appendix A - Country list by UN region and sub-region as used in our analysis (2017 data). Appendix B - Prevalence of clubfoot, JIA and JSLE by UN region and sub-region. Table 1. Estimated prevalence of clubfoot, JIA and JSLE by UN region in 2017, sorted in descending order of total population in 2017. Table 2. Estimated prevalence of clubfoot, JIA and JSLE by UN sub-region in 2017, sorted in descending order of total population in 2017. Appendix C - Estimated prevalence of clubfoot, JIA and JSLE by country in 2017, sorted in descending order of total population in 2017.

\section{Abbreviations}

CYP: Children and young people; DALYs: Disability adjusted life years; JIA: Juvenile Idiopathic Arthritis; JSLE: Juvenile Systemic Lupus Erythematosus; LRIC: Low Resource Income Countries; MRIC: Middle Resource Income Countries; MSK: Musculoskeletal; NCD: Non communicable diseases; SCFE: Slipped Capital Femoral Epiphysis; UK: United Kingdom; UN: United Nations; US: United States; WBG: World Bank Group; WHO: World Health Organisation

\section{Acknowledgements}

With permission, we thank Mrs. Janet Herdman for her secretarial support.

\section{Authors' contributions}

All authors approved the final manuscript as submitted and agree to be accountable for all aspects of the work. HF, MP and JR conceptualized and designed the study and reviewed and revised the manuscript. MD designed the data collection instruments, collected data, carried out the initial analyses, drafted the initial manuscript and reviewed and revised the manuscript.

\section{Funding}

This work had no specific funding support.

\section{Availability of data and materials}

All data generated or analysed during this study are included in this published article [and its supplementary information files].
Ethics approval and consent to participate

Ethical approval was not deemed appropriate for this study. Consent from patients is not applicable in this study.

\section{Consent for publication}

All authors give consent for publication.

\section{Competing interests}

The authors declare that they have no competing interests. The authors have no financial relationships relevant to this article to disclose.

Received: 2 February 2020 Accepted: 3 June 2020

Published online: 12 June 2020

\section{References}

1. James SL, Abate D, Abate KH, Abay SM, Abbafati C, Abbasi N, et al. Global, regional, and national incidence, prevalence, and years lived with disability for 354 diseases and injuries for 195 countries and territories, 1990-2017: a systematic analysis for the Global Burden of Disease Study 2017. Lancet. 2018;392(10159):1789-858.

2. Briggs AM, Woolf AD, Dreinhöfer K, Homb N, Hoy DG, Kopansky-Giles D, et al. Reducing the global burden of musculoskeletal conditions. Bull World Health Organ. 2018;96(5):366

3. Clark P. Ellis B. A public health approach to musculoskeletal health. Best Pract Res Clin Rheumatol. 2014;28(3):517-32.

4. Sebbag E, Felten R, Sagez F, Sibilia J, Devilliers H, Arnaud L. The world-wide burden of musculoskeletal diseases: a systematic analysis of the World Health Organization Burden of Diseases Database. Ann Rheum Dis. 2019; 78(6):844-8

5. WHO. World Health Organisation: Universal Health Coverage World Health Organisation; 2020 Available from: https://www.who.int/healthsystems/ universal_health_coverage/en. Accessed 10 Jan 2020

6. Tan A, Strauss VY, Protheroe J, Dunn KM. Epidemiology of paediatric presentations with musculoskeletal problems in primary care. BMC Musculoskelet Disord. 2018:19(1):40.

7. The World Bank Group. Who we are. World Bank Group. 2019. Available from: https://www.worldbank.org/en/who-we-are. Cited 14 Feb 2019.

8. Morris JK, Springett AL, Greenlees R, Loane M, Addor M-C, Arriola L, et al. Trends in congenital anomalies in Europe from 1980 to 2012. PLoS One. 2018;13(4):e0194986

9. Werler MM, Yazdy MM, Mitchell AA, Meyer RE, Druschel CM, Anderka M, et al. Descriptive epidemiology of idiopathic clubfoot. Am J Med Genet A 2013;161(7):1569-78

10. Bridgens J, Kiely N. Current management of clubfoot (congenital talipes equinovarus). BMJ. 2010;340:C355.

11. Grimes CE, Holmer H, Maraka J, Ayana B, Hansen L, Lavy CB. Costeffectiveness of club-foot treatment in low-income and middle-income countries by the Ponseti method. BMJ Glob Health. 2016;1(1):e000023.

12. Alavi $Y$, Jumbe $V$, Hartley $S$, Smith S, Lamping D, Muhit M, et al. Indignity, exclusion, pain and hunger: the impact of musculoskeletal impairments in the lives of children in Malawi. Disabil Rehabil. 2012;34(20):1736-46.

13. Ruperto N, Martini A. Current and future perspectives in the management of juvenile idiopathic arthritis. Lancet Child Adolesc Health. 2018;2(5):360 70.

14. Giancane G, Consolaro A, Lanni S, Davì S, Schiappapietra B, Ravelli A. Juvenile idiopathic arthritis: diagnosis and treatment. Rheumatol Ther. 2016; 3(2):187-207.

15. Thierry S, Fautrel B, Lemelle I, Guillemin F. Prevalence and incidence of juvenile idiopathic arthritis: a systematic review. Joint Bone Spine. 2014; $81(2): 112-7$

16. Consolaro A, Giancane G, Alongi A, van Dijkhuizen EHP, Aggarwal A, AlMayouf SM, et al. Phenotypic variability and disparities in treatment and outcomes of childhood arthritis throughout the world: an observational cohort study. Lancet Child Adolesc Health. 2019;3(4):255-63.

17. Saurenmann R, Rose J, Tyrrell P, Feldman B, Laxer R, Schneider $R$, et al. Epidemiology of juvenile idiopathic arthritis in a multiethnic cohort: ethnicity as a risk factor. Arthritis Rheum. 2007;56(6):1974-84.

18. Sawhney S, Manners P. The place of pediatric rheumatology in India. Indian J Pediatr. 2010;77(9):993-6.

19. Manners PJ. Epidemiology of the rheumatic diseases of childhood Curr Rheumatol Rep. 2003;5(6):453-7. 
20. Berntson L, Gäre BA, Fasth A, Herlin T, Kristinsson J, Lahdenne P, et al. Incidence of juvenile idiopathic arthritis in the Nordic countries. A population based study with special reference to the validity of the ILAR and EULAR criteria. J Rheumatol. 2003;30(10):2275-82.

21. Hiraki LT, Benseler SM, Tyrrell PN, Harvey E, Hebert D, Silverman ED. Ethnic differences in pediatric systemic lupus erythematosus. J Rheumatol. 2009; 36(11):2539-46.

22. Hiraki LT, Feldman CH, Liu J, Alarcón GS, Fischer MA, Winkelmayer WC, et al. Prevalence, incidence, and demographics of systemic lupus erythematosus and lupus nephritis from 2000 to 2004 among children in the US Medicaid beneficiary population. Arthritis Rheum. 2012;64(8):2669-76.

23. Kamphuis S, Silverman ED. Prevalence and burden of pediatric-onset systemic lupus erythematosus. Nat Rev Rheumatol. 2010;6(9):538.

24. Brunner HI, Gladman DD, Ibañez D, Urowitz MD, Silverman ED. Difference in disease features between childhood-onset and adult-onset systemic lupus erythematosus. Arthritis Rheum. 2008:58(2):556-62.

25. Huang J, Yeh K, Yao T, Huang Y, Chung H, Ou L, et al. Pediatric lupus in Asia. Lupus. 2010;19(12):1414-8.

26. Spittal GW, Lewandowski LB, Scott C. A clinical update on paediatric lupus. S Afr Med J. 2015;105(12):1075.

27. Pineles $\mathrm{D}$, Valente A, Warren B, Peterson M, Lehman T, Moorthy L. Worldwide incidence and prevalence of pediatric onset systemic lupus erythematosus. Lupus. 2011;20(11):1187-92.

28. Methodology-Standard country or area codes for statistical use (M49)Geographic Regions. United Nations Statistics Division. 2019. Available from: https://unstats.un.org/unsd/methodology/m49/. Cited 23 Jan 2019.

29. Scott C, Chan M, Slamang W, Okong'o L, Petty R, Laxer RM, et al. Juvenile arthritis management in less resourced countries (JAMLess): consensus recommendations from the Cradle of Humankind. Clin Rheumatol. 2019; 38(2):563-75.

30. Scott C, Webb K. Paediatric rheumatology in sub-Saharan Africa: Oxford University Press. Rheumatol. 2014;53(8):1357-8. https://doi.org/10.1093/ rheumatology/ket430.

31. Bhutani J, Bhutani S. Worldwide burden of diabetes. Indian J Endocrinol Metab. 2014;18(6):868.

32. Alatab S, Sepanlou SG, Ikuta K, Vahedi H, Bisignano C, Safiri S, et al. The global, regional, and national burden of inflammatory bowel disease in 195 countries and territories, 1990-2017: a systematic analysis for the Global Burden of Disease Study 2017. Lancet Gastroenterol Hepatol. 2020;5(1):17-30.

33. Henrickson M. Policy challenges for the pediatric rheumatology workforce: Part III. the international situation. Pediatr Rheumatol. 2011;9(1):26.

34. Arkachaisri T. Pediatric rheumatology in Southeast Asia: insights from the Singapore experience. Curr Rheumatol Rep. 2011;13(2):117-22.

35. Foster H, Rapley T. Access to pediatric rheumatology care -- a major challenge to improving outcome in juvenile idiopathic arthritis. J Rheumatol. 2010;37(11):2199-202.

36. Harper BD, Waceke Nganga RA, Forsyth KD, Ham HP, Keenan WJ, Russ CM Where are the paediatricians? An international survey to understand the global paediatric workforce. BMJ Paediatr Open. 2019;3:e000397. https://doi. org/10.1136/bmjpo-2018-000397.

37. Symmons D, Jones M, Osborne J, Sills J, Southwood T, Woo P. Pediatric rheumatology in the United Kingdom: data from the British Pediatric Rheumatology Group National Diagnostic Register. J Rheumatol. 1996; 23(11):1975-80.

38. Kocher MS, Bishop JA, Weed B, Hresko MT, Millis MB, Kim YJ, et al. Delay in diagnosis of slipped capital femoral epiphysis. Pediatrics. 2004;113(4):e322-e5.

39. The Paediatric Global Musculoskeletal Task Force 2020. Available from: https://gmusc.com/musculoskeletal-problems-in-children-and-youngpeople/. Accessed 10 Jan 2020

\section{Publisher's Note}

Springer Nature remains neutral with regard to jurisdictional claims in published maps and institutional affiliations.

Ready to submit your research? Choose BMC and benefit from:

- fast, convenient online submission

- thorough peer review by experienced researchers in your field

- rapid publication on acceptance

- support for research data, including large and complex data types

- gold Open Access which fosters wider collaboration and increased citations

- maximum visibility for your research: over $100 \mathrm{M}$ website views per year

At BMC, research is always in progress.

Learn more biomedcentral.com/submissions 